\title{
RENDIMENTO DAS VÍSCERAS DE CABRITOS MESTIÇOS ANGLO $x$ SRD E BOER x SRD ${ }^{1}$
}

\author{
Viscera yield from crossbred goats Anglo x SRD and Boer x SRD
}

\author{
Antonia Lucivania de Sousa Monte ${ }^{2}$, Arturo Bernardo Selaive-Villarroel ${ }^{3}$, Antonio Nunes de Oliveira ${ }^{4}$, \\ Juan Ramon Olalquiaga Perez ${ }^{5}$, Jorge Fernando Fuentes Zapata ${ }^{6}$, Rafael Elias Ramos ${ }^{7}$
}

\begin{abstract}
RESUMO
Objetivou-se com este estudo avaliar o rendimento das vísceras e gorduras cavitárias de caprinos cruzas Anglo Nubiana x Sem Raça Definida (AN) e Boer x SRD (BO). Foram utilizados 14 animais, abatidos com idade média de 12 meses e peso vivo médio de $28 \mathrm{~kg}$. As vísceras bucal e torácica, representadas pela língua, pulmões, traquéia, esôfago e coração, apresentaram rendimento médio total de 3,63 \% do peso do corpo vazio (PCV), sendo 3,79 \% para os mestiços (BO) e 3,48 \% para os mestiços (AN), não tendo diferença significativa entre ambos grupos genéticos. O rendimento médio total das vísceras abdominais representada pelo fígado, rins e pelas do trato digestivo, foi de 11,28 \%, sendo de $11,63 \%$ para nos mestiços BO e 10,96\% nos mestiços AN, sem diferença significativa entre os grupos. A gordura abdominal, mesentérica e omental, dos animais estudados apresentou rendimento médio de $2,97 \%$ do PCV, sendo que os mestiços BO tiveram maior $(\mathrm{P}<0,05)$ rendimento $(3,47 \%)$ que os AN $(2,48 \%)$. Conclui-se que os caprinos mestiços oriundos do cruzamento de reprodutores das raças Boer e Anglo Nubiana com cabras SRD não apresentam diferença no peso e no rendimento de vísceras utilizadas na alimentação humana, mostrando não haver efeito da raça do reprodutor nas características referidas. As vísceras de consumo humano representam em torno de $15 \%$ do peso do corpo vazio, razão pela qual devem ser mais valorizada no processo de comercialização.
\end{abstract}

Termos para indexação: Caprino, vísceras, gordura abdominal.

\section{ABSTRACT}

With the objective to evaluate the yield of viscera and cavitary fat of crossbred goats from Anglo Nubian and Boer sires and not well-defined type (SRD), an experiment was carried out. Fourteen animals, being seven $1 / 2$ Boer x $1 / 2$ SRD (BO) and seven $1 / 2$ Anglo Nubian x $1 / 2$ SRD (AN), were slaughtered at 12 months of age and $28 \mathrm{~kg}$ live weight, respectively. Viscera from the mouth and thoracic cavity represented $3,63 \%$ of the total empty body weight (EBW), with values of $3,79 \%$ for $\mathrm{BO}$ and $3,48 \%$ for AN, with no differences between groups. Average abdominal viscera yield, including liver, kidney and the gastro-intestinal tract was $11,28 \%$ of the EBW, being $11,63 \%$ for the BO group and $10,96 \%$ for the AN group, without any difference between these groups. Total fat, mesenteric and omental yield for the animals studied was 2,97\%. Abdominal fat content in the BO group $(3,47 \%)$, however, was higher $(\mathrm{P}<0,05)$ than the BO group $(2,48 \%)$. It was concluded that crossbreed goats from Boer and Anglo-Nubian buck with SRD did not show differences in weight and yield of the main edible viscera. This fact indicates that there is no effect of sire breed on these traits. Edible viscera represent about $15 \%$ of the empty body weight and should be considered as good prospect to aggregate value to the commercial price of goat.

Index terms: Goat, viscera, abdominal and total fat.

\section{(Recebido para publicação em 19 de abril de 2005 e aprovado em 6 de junho de 2006)}

\section{INTRODUÇÃO}

Após o abate, além da carcaça obtêm-se do animal certa quantidade de subprodutos, conhecidos como componentes não carcaça, que são aproveitados para processamento industrial e utilizados como fonte alternativa de alimento.

A importância dos componentes não carcaça não está vinculada apenas ao retorno econômico, mas também pela alternativa do uso de alguns órgãos como fonte alimentar, principalmente na população de baixo poder aquisitivo. As vísceras utilizadas para o consumo humano, constituem uma importante fonte de proteína animal, sendo o valor nutritivo desses órgãos compatível ou superior ao da carcaça (ROSA et al., 1985; YAMAMOTO et al., 2004). Em caprinos, o rúmen, intestino, coração e fígado apresentam elevados níveis de proteína com valores médios de $15,0 \%, 27,0 \%, 12,5 \%, 14,5 \%$ e $19,5 \%$, respectivamente, além de serem excelentes fontes de ferro (médias de $14,9 \mathrm{mg}$ / $100 \mathrm{~g}$ no intestino, $13,4 \mathrm{mg} / 100 \mathrm{~g}$ no fígado, $12,1 \mathrm{mg} / 100 \mathrm{~g}$ no

\footnotetext{
${ }^{1}$ Financiado pelo CNPq.

2 Professora do Instituto CENTEC, Doutoranda em Zootecnia da Universidade Federal do Ceará/UFC - Av. da Universidade, 2853 - Benfica 60.020-181 - Fortaleza, CE - lucymonte@uol.com.br

${ }^{3}$ Professor Adjunto do Departamento de Zootecnia da Universidade Federal do Ceará/UFC- Av. da Universidade, 2853 - Benfica - 60.020-181 Fortaleza, CE.

${ }^{4}$ Doutorando em Zootecnia na Universidade Federal do Ceará/UFC - Av. da Universidade, 2853 - Benfica - 60.020-181 - Fortaleza, CE.

${ }_{5}^{5}$ Professor Titular do Departamento de Zootecnia da Universidade Federal de Lavras/UFLA - Cx. P. 3037 - 37200-000 - Lavras/MG.

${ }^{6}$ Professor Titular do Departamento de Tecnologia de Alimentos da Universidade Federal do Ceará/UFC- Av. da Universidade, 2853 - Benfica 60.020-181 - Fortaleza, CE

${ }^{7}$ Graduando de Agronomiana Universidade Federal do Ceará/UFC - Av. da Universidade, 2853 - Benfica - 60.020-181 - Fortaleza, CE.
} 
coração e 8,7 mg/100 g no rúmen), segundo descrito por Madruga et al. (2003). Todavia, as vísceras caprinas apresentam maiores níveis de ácidos graxos saturados que os presentes nas carne e menores valores de ácidos graxos insaturados, ácidos graxos polinsaturados (BANSKALIEVA et al., 2000).

Do peso vivo do animal, os componentes não carcaça podem representar mais de 50,0\%, sendo este percentual influenciado pela genética, idade, sexo, tipo de nascimento e alimentação, parâmetros responsáveis pelas variações no peso do animal (CARVALHO et al., 2005).

$\mathrm{O}$ rendimento dos constituintes não pertencentes à carcaça é calculado em relação ao peso do corpo vazio (PCVZ), representado pelos componentes do peso vivo do animal menos o conteúdo do trato gastrointestinal, da bexiga e da vesícula. Isso contribui para obtenção de dados mais consistentes uma vez que o conteúdo gastrointestinal pode variar de 10 a $20 \%$ do peso vivo, em função do sistema de alimentação (TONETTO et al., 2004).

Dos componentes não carcaça, as vísceras representadas pelo coração, pulmões, fígado, rins, intestinos e estômagos, podem representar em média $20 \%$ do peso vivo, um rendimento extremamente significativo que pode ser revertido em lucro para o produtor, visto que estas podem ser utilizadas na culinária. Normalmente, os pesos das vísceras aumentam proporcionalmente com o aumento do peso de abate (COSTA et al., 2005).

$\mathrm{Na}$ cadeia produtiva animal, todos os segmentos envolvidos, que vão do produtor até o consumidor, tem finalidade lucrativa. Nesse sentido, para que haja uma melhor valorização da produção animal, a comercialização deveria ser feita considerando o animal como um todo, valorizando além da carcaça, os componentes não carcaça, visto que estes apresentam estreita relação com o rendimento de carcaça (CARVALHO et al., 2005). Assim, é importante a obtenção de informações das vísceras, principalmente as utilizadas na alimentação, cuja comercialização agregará maior valor econômico ao animal.

Com este trabalho, objetivou-se avaliar o peso e rendimento das vísceras e gorduras internas, em relação ao peso do corpo vazio, em caprinos mestiços meio sangue Boer e Anglo Nubiana com SRD.

\section{MATERIAL E MÉTODO}

O experimento foi conduzido no Departamento de Zootecnia da Universidade Federal do Ceará, utilizando-se caprinos mestiços, provenientes do cruzamento de reprodutores caprinos das raças Boer e Anglo Nubiana com cabras sem padrão racial definido (SRD), mantidos em sistema semi-intensivo de criação. Foram avaliadas as vísceras de 14 cabritos, sendo 07 animais 1/2 Boer x 1/2 SRD (mestiços Boer) e $071 / 2$ Anglo Nubiana x 1/2 SRD (mestiços Anglo Nubiana), abatidos em média com 10 meses de idade e $28 \mathrm{~kg}$ de peso vivo (PV) e com rendimento médio de $23 \mathrm{~kg}$ de Peso do Corpo Vazio (PCVZ). Para determinar o PCV, foi subtraído do peso do animal vivo, o peso dos conteúdos do trato digestório, da vesícula biliar e da bexiga. Foram pesados em conjunto, traquéia, esôfago e pulmões. Língua, coração, fígado, rins, rúmen/retículo, omaso, abomaso, intestino delgado, intestino grosso, gordura mesentérica e gordura omental, foram pesados separadamente. $\mathrm{O}$ rendimento médio percentual de todas as vísceras e gorduras internas foi calculado com base no PCVZ, conforme a técnica descrita por Oliveira et al. (2002).

$\mathrm{O}$ delineamento experimental foi inteiramente casualizado e os dados foram analisados pelo procedimento GLM do programa SAS. As variáveis estudadas foram submetidas ao teste de Tukey para comparação de médias em um nível de 5\% de significância.

\section{RESULTADOS E DISCUSSÃO}

Os valores médios de peso e rendimento das vísceras abdominais, representadas pelo fígado, rins, rúmen/retículo, omaso, abomaso, intestinos delgado e grosso encontramse na Tabela 1. Como já era esperado, por serem os caprinos animais ruminantes, as vísceras da região abdominal apresentaram rendimentos superiores às vísceras torácicas e bucal, com valor médio de $11,28 \% \pm 1,19$, sendo $11,63 \% \pm$ 1,23 para os mestiços Boer e 10,96\% $\pm 1,16$ para os mestiços Anglo Nubiana, não havendo diferença significativa $(\mathrm{P}>0,05)$ entre os grupos de animais. Os valores encontrados são superiores aos observados por Ferreira et al. (2002), em cabritos Saanem abatidos com $35 \mathrm{~kg}$ de peso vivo que relataram valores $0,67 \mathrm{~kg}$ e 2,41 para peso e rendimento do rúmen/retículo, de $0,08 \mathrm{~kg}$ e $0,31 \%$ para o omaso e de $0,14 \mathrm{~kg}$ e $0,51 \%$ para o abomaso.

$\mathrm{O}$ peso e rendimento médio do fígado foi de $0,56 \pm$ $0,01 \mathrm{~kg}$ e $2,54 \pm 0,01 \%$, respectivamente. Rendimento semelhante foi verificado por Mahgoub \& Lu (1998), em caprinos Árabes das raças Batina $(2,4 \%)$ e Dhofari $(2,1 \%)$. A similaridade de peso e rendimento das vísceras deste trabalho em relação às citadas na literatura deve-se fundamentalmente ao peso de abate muito similar dos caprinos. $\mathrm{O}$ efeito do peso de abate do animal no peso e rendimento das vísceras tem sido descrita em ovinos. Assim, Oliveira et al. (2002) encontraram em ovinos, abatidos com peso médio de $45 \mathrm{~kg}$ valores superiores para o fígado $(0,611 \mathrm{~kg}$ e $0,671 \mathrm{~kg}$ em animais Santa Inês e Bergamácia, respectivamente). Enquanto Rosa et al. (2002) encontraram rendimentos percentuais ligeiramente inferior $(2,01 \%)$, em cordeiros da raça Texel abatidos com $25 \mathrm{~kg}$ de peso vivo. 
Os valores médios de peso e rendimento do conjunto traquéia, esôfago e pulmões, bem como do coração e da língua, encontram-se na Tabela 2 . O rendimento médio total dessas vísceras foi de 3,63\% \pm 1,22 , sendo $3,79 \% \pm 1,29$ para os mestiços Boer e de 3,48 $\% \pm 1,16$ para os mestiços Anglo Nubiana, sem diferença significativa $(\mathrm{P}>0,05)$ entre esses grupos genéticos. Dentre as vísceras bucal e torácicas, o conjunto traquéia, esôfago e pulmões, destaca-se como o de maior peso $(0,568 \mathrm{~kg} \pm$ $0,01)$ e maior rendimento $(2,61 \% \pm 0,27)$.

Peso semelhante para a língua $(0,09 \mathrm{~kg})$ foi encontrado por Rosa et al. (1985), em caprinos SRD nativos do Nordeste. Já para o coração, Bueno et al. (1999) descreveram em cabritos da raça Saanen, abatidos aos 22 $\mathrm{kg}$ de peso vivo, valores de rendimento inferior $(0,42 \%)$ aos obtidos neste estudo (Tabela 2). Além das diferenças no peso de abate dos animais, as diferenças no rendimento de coração podem se dever a influência da técnica de separação dos órgãos utilizada pelos diferentes autores, a qual nem sempre segue exatamente a linha de demarcação anatômica.

Os resultados indicam que aproximadamente $15 \%$ do peso corporal vazio do animal está representado pelas vísceras destinadas ao consumo humano, valor semelhante foi encontrado por Atti et al. (2000) em ovelhas adultas da raça Barbary. Esta informação pode auxiliar na determinação da quantificação dos órgãos que têm valor econômico e pode agregar valor à produção caprina. Os resultados enfatizam a importância de ser considerado no valor do animal, além do peso e qualidade de carcaça, o rendimento das vísceras utilizadas nas alimentação humana.

Em relação à gordura acumulada nos órgãos, o peso médio da gordura abdominal (mesentério e omento) foi de $0,72 \mathrm{~kg} \pm 0,02$ representando $2,97 \% \pm 0,09$ do peso do corpo vazio, com valores semelhantes nos cabritos Boer e Anglo Nubiano, conforme se observa na Tabela 3.

Em caprinos mestiços Boer x Saanen, abatidos aos $30 \mathrm{~kg}$ de peso vivo, Dhanda et al. (2003) verificaram que a gordura interna composta pelas gorduras mesentérica e omental, apresentou rendimento de $2,59 \%$ do peso do corpo vazio, valor muito próximo ao observado neste trabalho.

Com relação à gordura mesentérica, a dos cabritos mestiços Boer apresentou peso de $0,402 \mathrm{~kg}$ e rendimento de $1,73 \%$, sendo superior $(\mathrm{P}<0,05)$ a dos mestiços Anglo Nubiana com peso de $0,278 \mathrm{~kg}$ e rendimento de $1,11 \%$.

A gordura é o componente que apresenta maior variação em função do tipo de alimentação. $\mathrm{O}$ aumento na quantidade da gordura interna comprova a habilidade fisiológica que o animal possui em depositar gordura intraabdominal. Segundo Alves et al. (2003), a maior proporção de gordura interna, acarreta na prática, maiores exigências de energia de mantença, em razão da maior atividade metabólica do tecido adiposo. No caso de caprinos da

TABELA 1 - Media de peso e rendimento de vísceras abdominais, em relação ao peso do corpo vazio, de cabritos mestiços Boer e Anglo Nubiana.

\begin{tabular}{|c|c|c|c|c|c|c|}
\hline \multirow{3}{*}{ Vísceras vazias } & \multicolumn{4}{|c|}{ Grupo genético (*) } & \multirow{2}{*}{\multicolumn{2}{|c|}{$\begin{array}{l}\text { Média geral } \\
(\mathrm{n}=14)\end{array}$}} \\
\hline & \multicolumn{2}{|c|}{$\begin{array}{c}\text { Mestiços Boer } \\
\quad(\mathrm{n}=07)\end{array}$} & \multicolumn{2}{|c|}{$\begin{array}{c}\text { Mestiços Anglo Nubiana } \\
(\mathrm{n}=07)\end{array}$} & & \\
\hline & $\mathbf{K g}$ & $\%$ & Kg & $\%$ & Kg & $\%$ \\
\hline Fígado & $0,55 \pm 0,12$ & $2,49 \pm 0,17$ & $0,57 \pm 0,02$ & $2,60 \pm 0,36$ & $0,56 \pm 0,01$ & $2,54 \pm 0,09$ \\
\hline Rins & $0,09 \pm 0,01$ & $0,42 \pm 0,04$ & $0,09 \pm 0,01$ & $0,40 \pm 0,04$ & $0,09 \pm 0,00$ & $0,41 \pm 0,01$ \\
\hline Rúmen/Retículo & $0,70 \pm 0,15$ & $3,18 \pm 0,04$ & $0,74 \pm 0,13$ & $3,20 \pm 0,05$ & $0,72 \pm 0,02$ & $3,19 \pm 0,03$ \\
\hline Omaso & $0,11 \pm 0,02$ & $0,53 \pm 0,03$ & $0,11 \pm 0,02$ & $0,50 \pm 0,06$ & $0,11 \pm 0,01$ & $0,51 \pm 0,02$ \\
\hline Abomaso & $0,17 \pm 0,02$ & $0,76 \pm 0,02$ & $0,17 \pm 0,03$ & $0,75 \pm 0,04$ & $0,17 \pm 0,01$ & $0,75 \pm 0,07$ \\
\hline Intestino delgado & $0,68 \pm 0,02$ & $3,16 \pm 0,18$ & $0,55 \pm 0,09$ & $2,50 \pm 0,05$ & $0,61 \pm 0,09$ & $2,83 \pm 0,46$ \\
\hline Intestino grosso & $0,25 \pm 0,04$ & $1,09 \pm 0,05$ & $0,24 \pm 0,02$ & $1,01 \pm 0,04$ & $0,24 \pm 0,01$ & $1,05 \pm 0,05$ \\
\hline Total & $2,55 \pm 0,27$ & $11,63 \pm 1,23$ & $2,47 \pm 0,26$ & $10,96 \pm 1,16$ & $2,5 \pm 0,26$ & $11,28 \pm 1,19$ \\
\hline
\end{tabular}

(*) Não houve diferença significativa $(\mathrm{P}>0,05)$ entre os grupos genéticos. 
TABELA 2 - Pesos (kg) e rendimentos (\%) de vísceras bucal e torácicas, em relação ao peso do corpo vazio, de cabritos mestiços Boer e Anglo Nubiana.

\begin{tabular}{|c|c|c|c|c|c|c|}
\hline \multirow{3}{*}{ Vísceras } & \multicolumn{4}{|c|}{ Grupo genético $(*)$} & \multirow{2}{*}{\multicolumn{2}{|c|}{$\begin{array}{l}\text { Média geral } \\
\quad(\mathrm{n}=14)\end{array}$}} \\
\hline & \multicolumn{2}{|c|}{$\begin{array}{l}\text { Mestiços Bôer } \\
\quad(\mathrm{n}=07)\end{array}$} & \multicolumn{2}{|c|}{$\underset{(\mathrm{n}=07)}{\text { Mestiços Anglo Nubiana }}$} & & \\
\hline & Kg & $\%$ & Kg & $\%$ & Kg & $\%$ \\
\hline Língua & $0,084 \pm 0,01$ & $0,35 \pm 0,03$ & $0,088 \pm 0,01$ & $0,27 \pm 0,04$ & $0,086 \pm 0,002$ & $0,31 \pm 0,09$ \\
\hline $\begin{array}{l}\text { Traquéia, } \\
\text { esôfago, pulmões }\end{array}$ & $0,597 \pm 0,09$ & $2,74 \pm 0,48$ & $0,575 \pm 0,05$ & $2,48 \pm 0,48$ & $0,568 \pm 0,01$ & $2,61 \pm 0,27$ \\
\hline Coração & $0,153 \pm 0,05$ & $0,70 \pm 0,01$ & $0,166 \pm 0,04$ & $0,73 \pm 0,08$ & $0,159 \pm 0,009$ & $0,71 \pm 0,06$ \\
\hline Total & $0,834 \pm 0,27$ & $3,79 \pm 1,29$ & $0,829 \pm 0,26$ & $3,48 \pm 1,16$ & $0,813 \pm 0,25$ & $3,63 \pm 1,22$ \\
\hline
\end{tabular}

$(*)$ Não houve diferença significativa $(\mathrm{P}>0,05)$ entre os grupos genéticos.

TABELA 3 - Pesos $(\mathrm{kg})$ e rendimentos (\%) das gorduras abdominais, em relação ao peso do corpo vazio de cabritos mestiços Boer e Anglo Nubiana.

\begin{tabular}{|c|c|c|c|c|c|c|}
\hline \multirow{3}{*}{$\begin{array}{l}\text { Gordura } \\
\text { abdominal }\end{array}$} & \multicolumn{4}{|c|}{ Grupo genético } & \multirow{2}{*}{\multicolumn{2}{|c|}{$\begin{array}{l}\text { Média geral } \\
\quad(\mathrm{n}=14)\end{array}$}} \\
\hline & \multicolumn{2}{|c|}{$\begin{array}{c}\text { Mestiços Bôer } \\
(\mathrm{n}=07)\end{array}$} & \multicolumn{2}{|c|}{$\begin{array}{c}\text { Mestiços Anglo Nubiana } \\
(\mathrm{n}=07)\end{array}$} & & \\
\hline & Kg & $\%$ & $\mathbf{K g}$ & $\%$ & Kg & $\%$ \\
\hline Mesentério & $0,402 \pm 0,09 \mathrm{a}$ & $1,73 \pm 0,03 \mathrm{a}$ & $0,278 \pm 0,01 b$ & $1,11 \pm 0,04 \mathrm{~b}$ & $0,342 \pm 0,08$ & $1,42 \pm 0,2$ \\
\hline Omento & $0,403 \pm 0,09 \mathrm{a}$ & $1,74 \pm 0,08 \mathrm{a}$ & $0,360 \pm 0,01 \mathrm{a}$ & $1,37 \pm 0,09 \mathrm{a}$ & $0,381 \pm 0,03$ & $1,55 \pm 0,2$ \\
\hline Total & $0,805 \pm 0,001 \mathrm{a}$ & $3,47 \pm 0,007 \mathrm{a}$ & $0,638 \pm 0,05 b$ & $2,48 \pm 1,18 b$ & $0,721 \pm 0,02$ & $2,97 \pm 0,09$ \\
\hline
\end{tabular}

Letras diferentes na mesma linha diferem estatisticamente $(\mathrm{P}<0,05)$.

raça Boer, altamente especializada para produção de carne, o acúmulo de gordura interna pode ser interpretado como um aspecto negativo pelo maior consumo de alimento. Isso pode acarretar em um aumento no custo de produção para a deposição de uma gordura sem maior valor econômico, ocasionando um desvio de energia, que poderia ser melhor aproveitada em outra parte do metabolismo animal. Todavia, deve-se considerar que o tecido adiposo mesentérico, pode constituir-se em uma reserva energética para o animal durante os períodos prolongados de seca, característicos da região Nordeste do Brasil. Lançando mão dessas reservas, o animal poderá reduzir a degradação de proteína muscular nessa época do ano.

\section{CONCLUSÃO}

Caprinos mestiços oriundos do cruzamento de reprodutores das raças Boer e Anglo Nubiana com cabras SRD não apresentam diferença no peso e no rendimento das vísceras utilizadas na alimentação humana, mostrando não haver efeito da raça do reprodutor nas características referidas.

Do peso do corpo vazio, $15 \%$ é representado pelas vísceras utilizadas na alimentação humanas e 3\% é representado pelas gorduras sem valor alimentar.

\section{REFERÊNCIAS BIBLIOGRÁFICAS}

ALVES, K. S.; CARVALHO, F. F. R.; FERREIRA, M. A. Níveis de energia em dietas para ovinos Santa Inês: característica de carcaça e constituintes não carcaça. Revista Brasileira de Zootecnia, Viçosa, v. 32, n. 6, p. 19271936, 2003. Suplemento 2.

ATTI, N.; NOZIÈRE, P.; DORERAU, M.; KAYOULI, C.; BOCQUIER, F. Effects of underfeeding and refeeding on offals weight in the Barbary ewes. Small Ruminant Research, [S.1.], n. 38, p. 37-43, 2000. 
BANSKALIEVA, V.; SAHLU, T.; GOETSCH, A. L. Fatty acid composition of gota muscles and fat depots: a review. Small Ruminant Research, [S.1.], v. 37, p. 255-268, 2000.

BUENO, M. S.; SANTOS, L. E.; CUNHA, E. A. Avaliação de carcaça de cabritos abatidos com diferentes pesos vivos.

Revista Nacional da Carne, São Paulo, ano 24, n. 273, p. 74-77, nov. 1999.

CARVALHO, S.; VERGUEIRO, A.; KIELING, R. Avaliação da suplementação concentrada em pastagem de Tifton-85 sobre os componentes não carcaça de cordeiros. Ciência Rural, Santa Maria, v. 15, n. 2, p. 435-439, 2005.

COSTA, R. G.; MEDEIROS, A. N.; MADRUGA, M. S.; SANTOS, N. M. Qualidade físico-química, química e microbiológica da buchada caprina. Revista Higiene Alimentar, São Paulo, v. 19, n. 130, p. 62-68, 2005.

DHANDA, J. S.; TAYLOR, D. G.; MURRAY, P. J. Growth, carcass and meat quality parameters of male goats: effects of genotype and liveweight at slaughter. Small Ruminant Research, [S.1.], v. 50, p. 57-66, 2003.

FERREIRA, A. C. D.; YANEZ, E. A.; RESENDE, K. T. Morfologia do trato gastrointestinal de caprinos Saanen submetidos a diferentes níveis alimentares. In: REUNIÃO ANUAL DA SOCIEDADE BRASILEIRA DE ZOOTECNIA, 2002, Recife, PE. Anais... Recife: SBZ, 2002.

MADRUGA, M. S.; REZER, J. S.; MELO, H. M. G. Caracterização química e microbiológica de vísceras caprinas destinadas ao preparo de buchada e picado. Revista Nacional da Carne, São Paulo, ano 27, v. 18, n. 316, p. 36-45, 2003.
MAHGOUB, O.; LU, C. D. Growth, body composition and carcass tissue distribution in goats of large and small sizes. Small Ruminant Research, [S.1.], v. 27, p. 267-278, 1998.

OLIVEIRA, M. V. M.; PÉREZ, J. R. O.; ALVES, E. L. Avaliação da composição de cortes comerciais, componentes corporais e órgãos internos confinados e alimentados com dejetos de suínos. Revista Brasileira de Zootecnia, Viçosa, v. 31, n. 3, p. 1459-1469, 2002. Suplemento.

ROSA, G. T.; PIRES, C. C.; SILVA, J. H. S. Proporções e coeficientes de crescimento dos não componentes da carcaça de cordeiros e cordeiros em diferentes métodos de alimentação. Revista Brasileira de Zootecnia, Viçosa, v. 31, n. 6, p. 2290-2298, 2002.

ROSA, J. S.; LEÓN, F. A. P.; RIERA, G. S.; SIMPLICIO, A. A. Caracterização dos tipos de cabras nativas brasileiras: avaliação de vísceras. Pesquisa Agropecuária Brasileira, Brasília, v. 20, n. 8, p. 873-990, 1985.

TONetTo, C. J.; PIRES, C. C.; MUlleR, L. Rendimentos de cortes da carcaça, características da carne e componentes do peso vivo em cordeiros terminados em três sistemas de alimentação. Revista Brasileira de Zootecnia, Viçosa, v. 33, n. 1, p. 234-241, 2004.

YAMAMOTO, S. M.; MACEDO, F. A. F.; MEXIA, A. A. Rendimento dos cortes e não componentes da carcaça de cordeiros terminados com dietas contendo diferentes fontes de óleo vegetal. Ciência Rural, Santa Maria, v. 34, n. 6, p. 1909-1913, 2004. 